\title{
SOURCES OF INFORMATION OF DATE PALM FARMERS IN AL-MADINAH AL-MONWARAH AREA, SAUDI ARABIA
}

\author{
(Received: 19. 3. 2013)
}

\author{
By \\ F. S. Al - Subaiee \\ Department of Agricultural Extension and Rural Society, Faculty of Food and Agricultural Sciences, \\ King Saud University, Saudi Arabia
}

\begin{abstract}
The main objectives of this research were to identify the sources of agricultural information of Date Palm farmers in Al-Madinah Al-Monwarah area, Saudi Arabia, to identify the personal socioeconomic characteristics of the respondents, and determine the relationships between farmers socioeconomic characteristics and their use of different sources of information. A questionnaire was used to collect the data from a simple consisted random sample of (180) farmers. Percentages, arithmetic means, standard deviation, and Pearson correlation coefficient were used to analyze the data, using SPSS program. The results indicated that the farmers depended on the Ministry of Agriculture and its directorates and branches, and other farmers as the two highest sources of agricultural information with a degree located between moderate and limited dependence level, with an average mean of 2.63 and 2.61, respectively. The results revealed that more than two-thirds $(68.8 \%)$ of the respondents were in the age group of 50 years and above, low level of education, and an average family size of 6 members. The results showed that farmers have long experience in agricultural work, and the majority of them $(70.6 \%)$ have relatively small farms area (less than 50 donum). Also, the study findings indicated that a significant correlation relationship was found between some of the farmer's characteristics and their dependence level of some sources of agricultural information. The study recommended enhancing the role of the Ministry of Agriculture and its directorates and branches as an important source of agricultural information, identifying and training farmers who have relationship abilities as information sources, encouraging farmers to use more sources of agricultural information such as agricultural colleges and scientific research centers, provision of agricultural information by using modern methods such as e-extension, and considering the diversity of farmers characteristics.
\end{abstract}

Key words: agricultural information source, date palm, farmers socioeconomic.

$$
\begin{aligned}
& \text { مصادر معلومات مزارعي النخيل بمنطقة المدينة المنورة بالمملكة العربية السعودية } \\
& \text { فيصل بن سلطان السبيعى }
\end{aligned}
$$

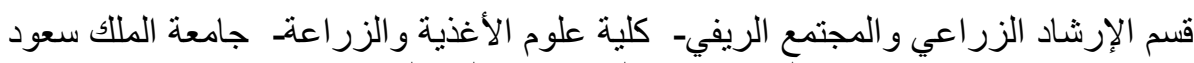

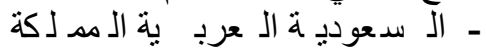

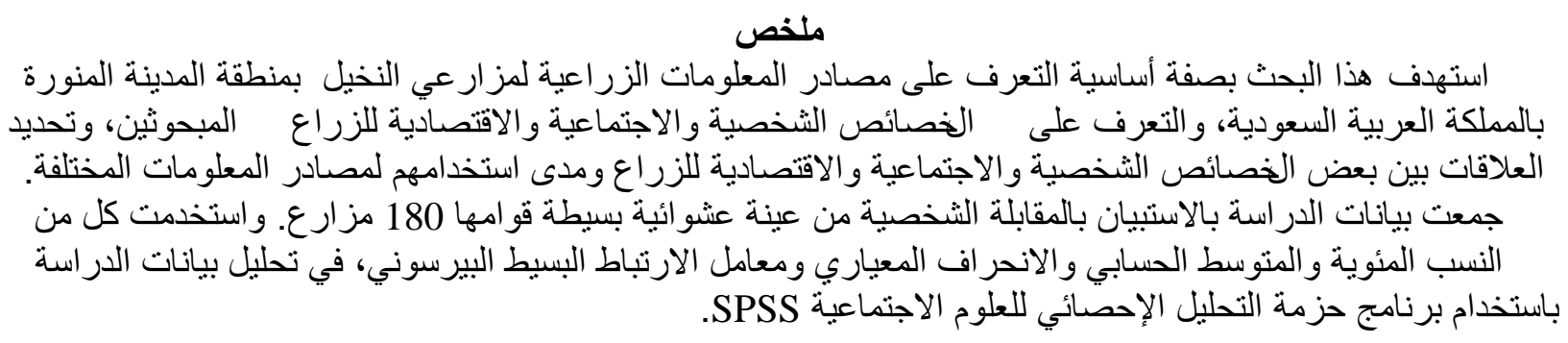




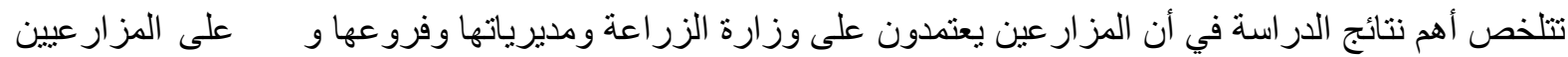

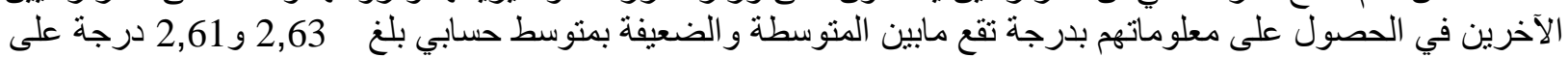

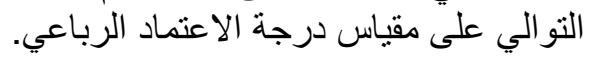

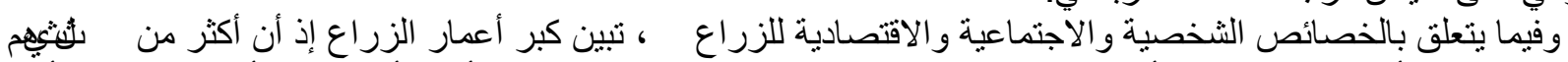

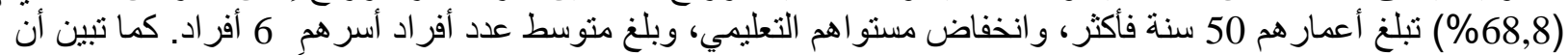

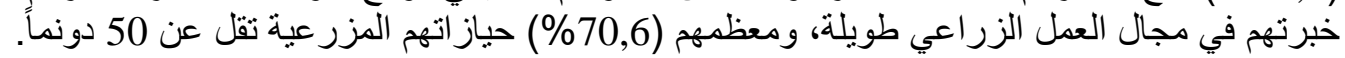

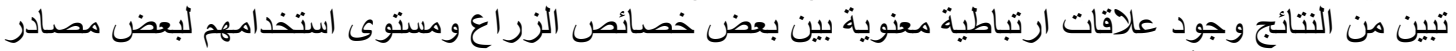

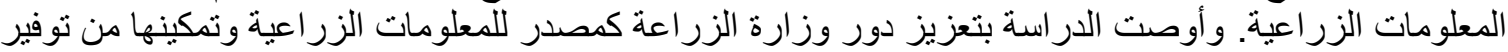

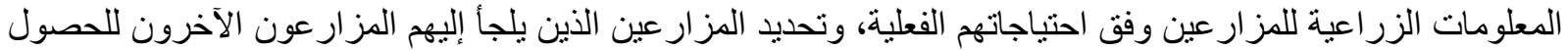

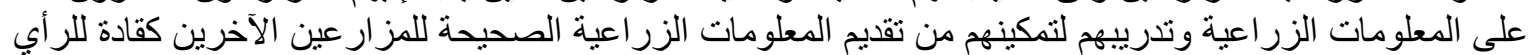

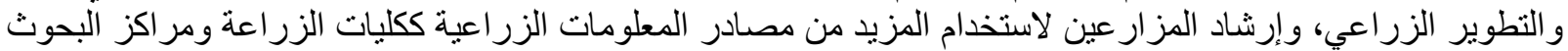

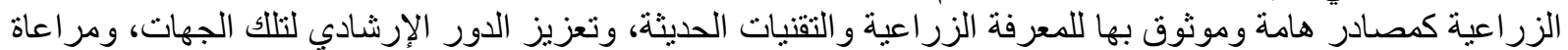

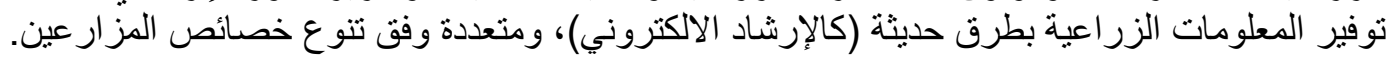

على تحسين مستوى معيشتهم و لا تقتصر فقط على نقل المعلومات الإرشادية الزر اعية.

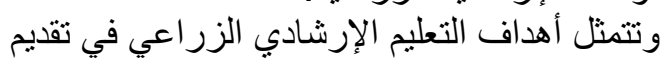

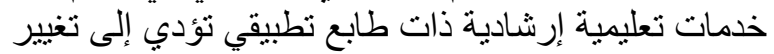

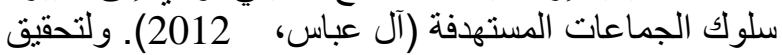

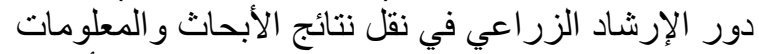

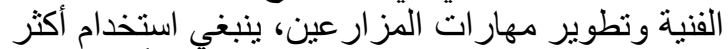

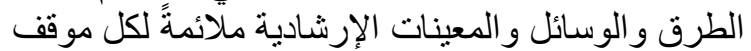

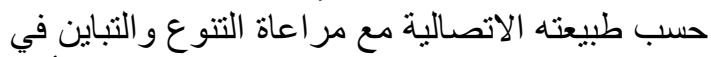

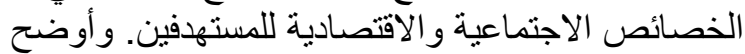

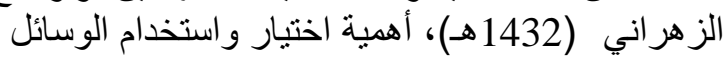

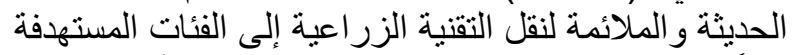

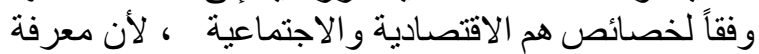

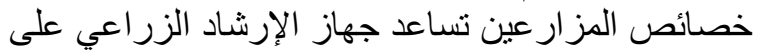

تصميم البرامج الإرشادية المناسبة لتحسين عمليات نقل الارثناد الزيات المعلومات الملائمة للمستفيدين.

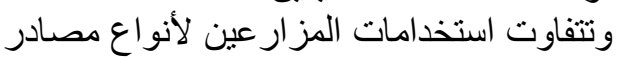

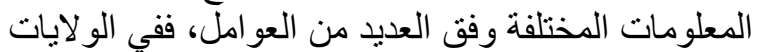

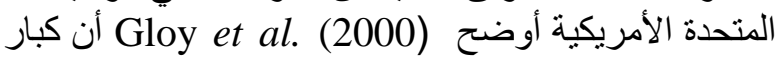

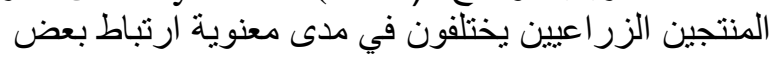

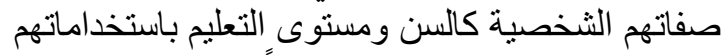

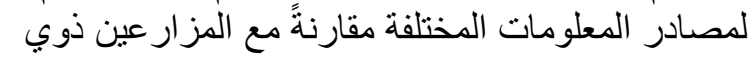

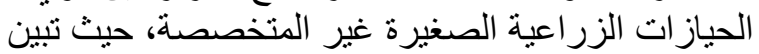

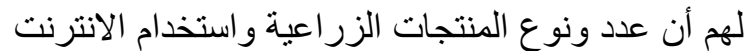
تعطي مؤشراً إيجابياً على اتجاهات كبار الزاعة المنتجين نحو الانترن مصنادر المعلومات المختلفة وجدواهيا.

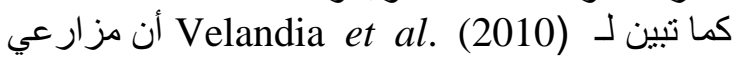
القطن في العديد من الو لايات المتحدة الأمريكية يستخدمون

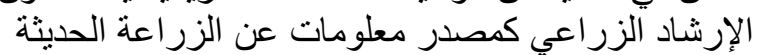

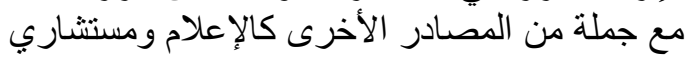

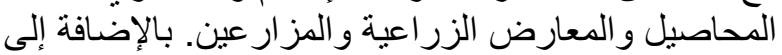

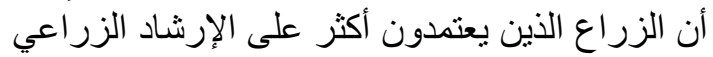

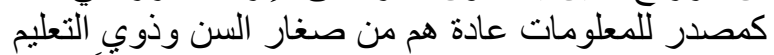

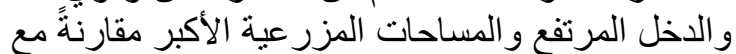
الزراع الذين لا يعتمدون على الإرشاد كمصدر للمعلوماتئ.

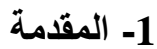

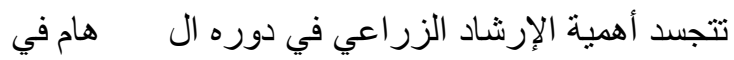

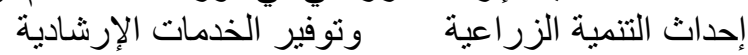

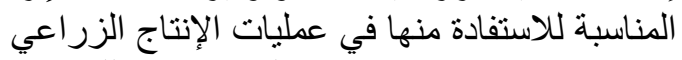

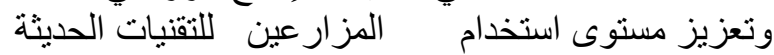
التحسين دخلهم ورفع مستويز اتهم الاقتصادية و الاجتماعية

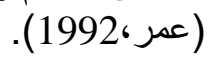
ويعد الإرشاد الزراعي من الأجهزة الهامة لدوره في

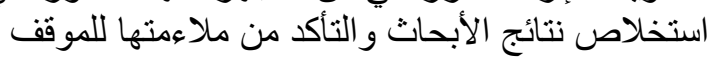

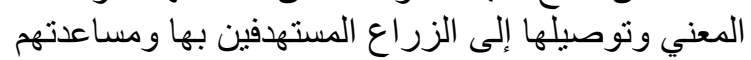

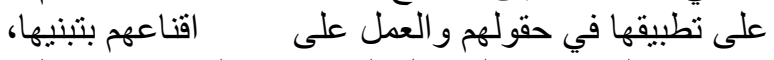

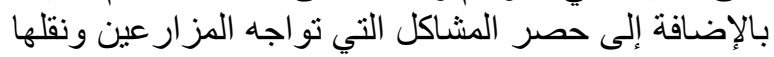

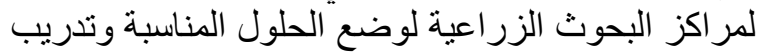

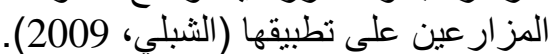

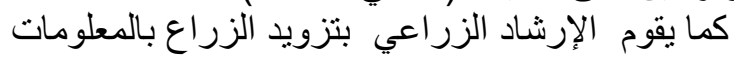

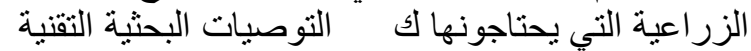

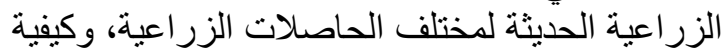

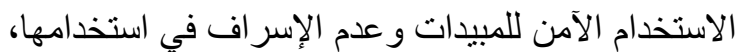

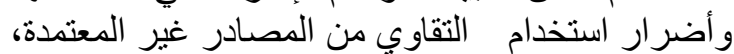

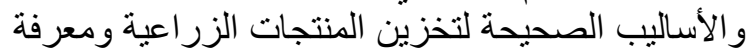

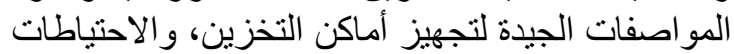

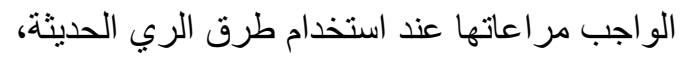

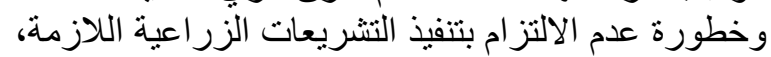

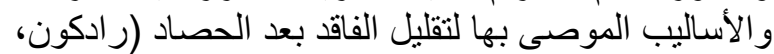
2013

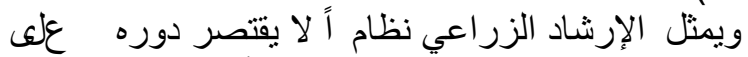

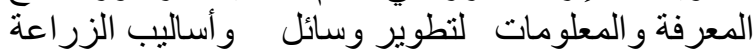

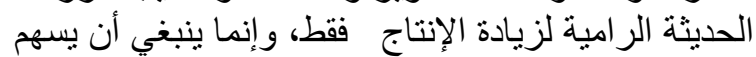

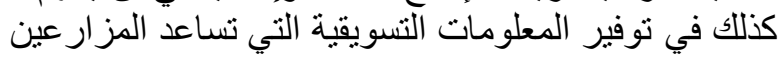

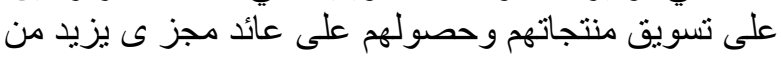

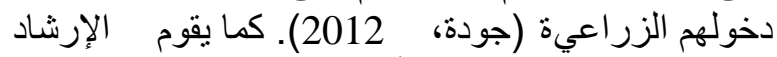

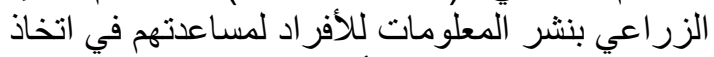
القرارات السليمة لزيادة الأرباح (Hall et al., 2003).

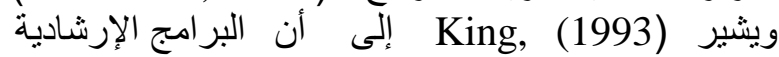
الزراعية الجيدة والناجحة هي التي تساعد المسترشدين الإنيادين 
و الإذاعة مر اكز متوسطة الاستخدام وجاءت المؤسسات

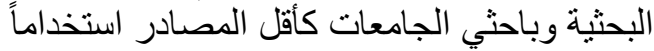

.(Demiryurek et al. 2008)

وفي الجمهورية اليمنية وجد الضريس (2009)، أن أهم أهم الزئ

مصادر الم علومات الزر اعية هي الجير الجية النين والأقارب

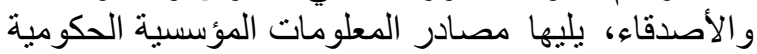

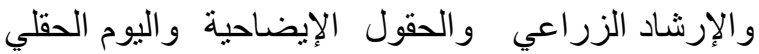

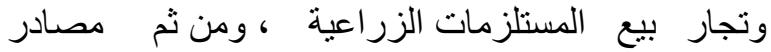

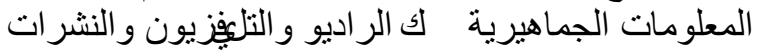
الإرشادية و الصحف الزر اعية والكتب الزئ الزر اعية.

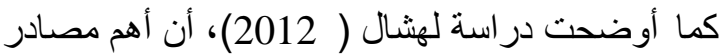

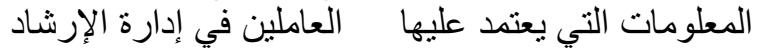

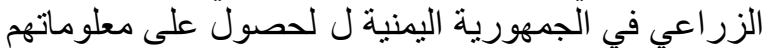

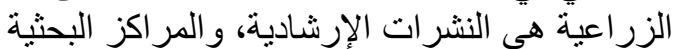
الزراعية، وآلكتب و المر اجع العلمية والدوراتية والدرات التدرييية،

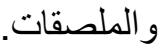

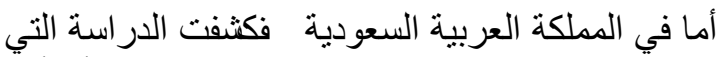

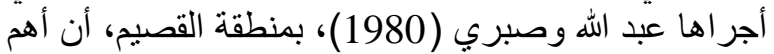

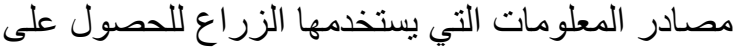

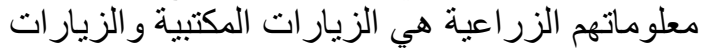

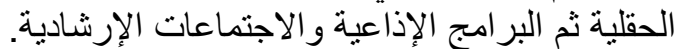

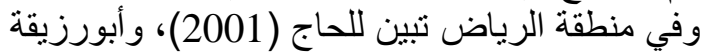

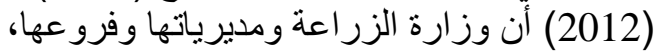

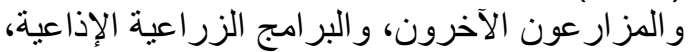

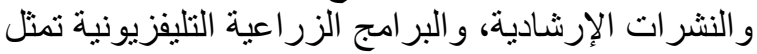

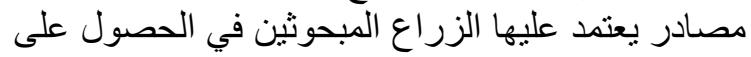

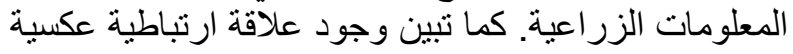

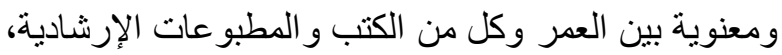

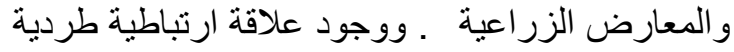

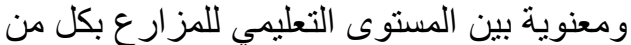

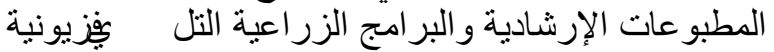

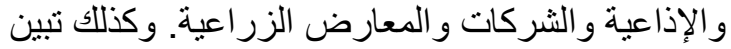

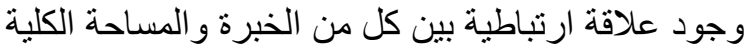

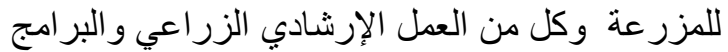

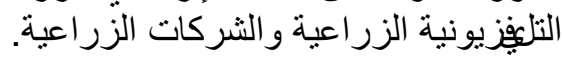

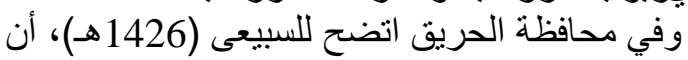

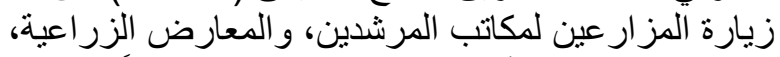

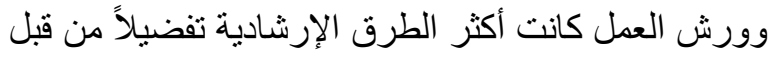

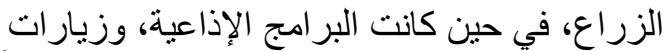

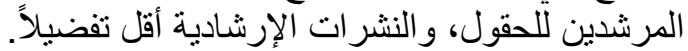

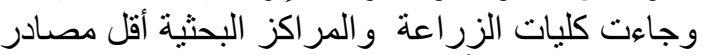

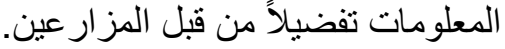

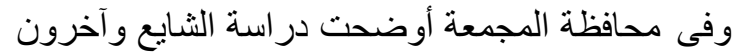

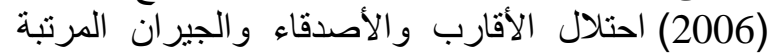

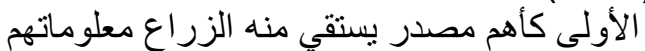

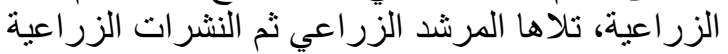

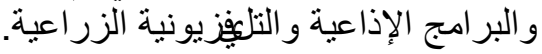
وفي مدينة نجران وجد آل عباس (2012)، أن أهم أله
تنبين في كندا أن مندوبي المبيعات الزر اعبة، و إدارة

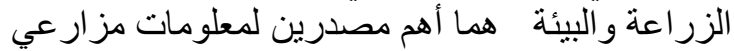

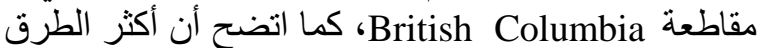

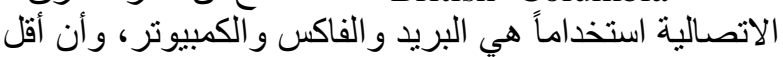

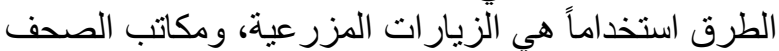
الزراعية، وكانت إصدار ات وزيارات وزارة الزر اعة بالية بالمقاطعة أكثر

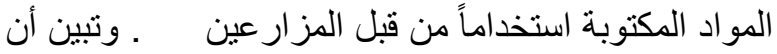

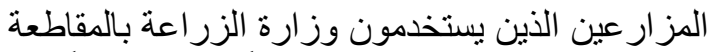

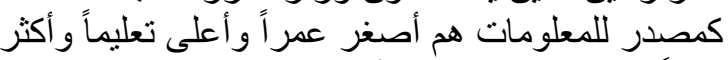

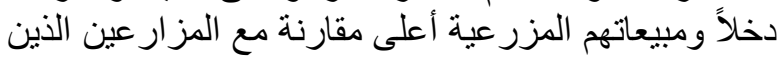
لا يستخدمونها (Shaw, 1993). كما ذكر (Babu et al. (2012) أن المزارعين بالهند

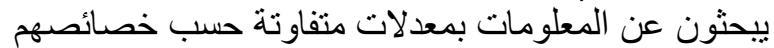

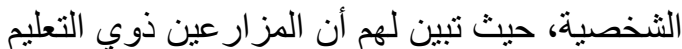

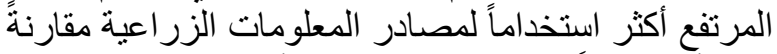

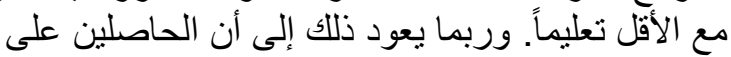

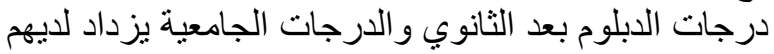

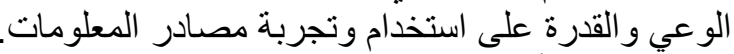

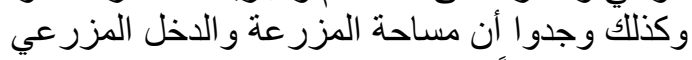

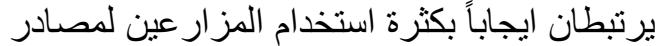

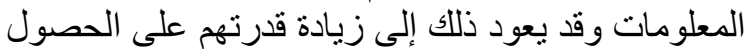

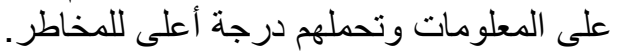

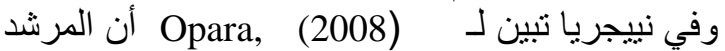

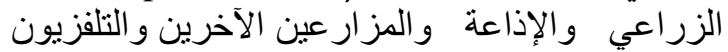

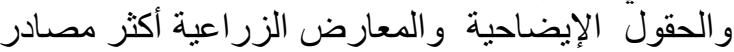

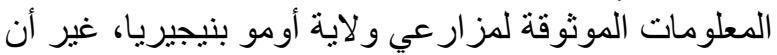

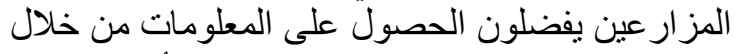

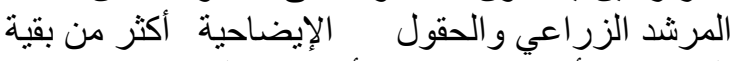

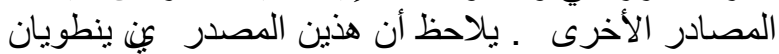

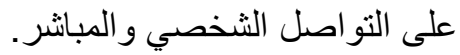

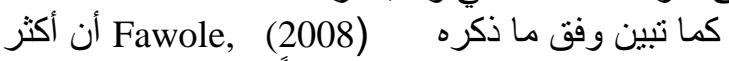

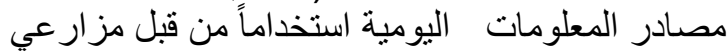

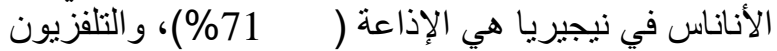

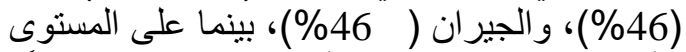

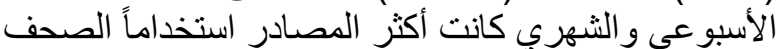

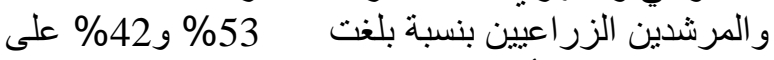

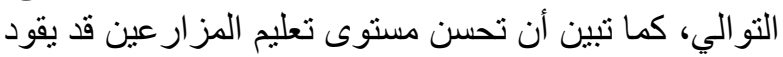
إلى زيادة فرص حصولهين الته على المعلومات الزين الزراعية

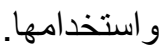

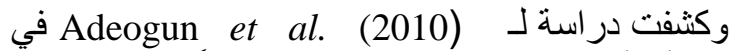
نيجيريا أن أكثر مصادر المعلومات استخداماً من قبل

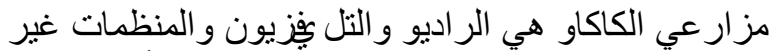

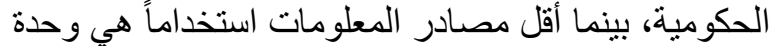

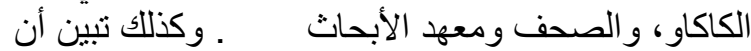
المزارعين الأقل عمر اً والأكثر تعليماً يستخدمون مصادر

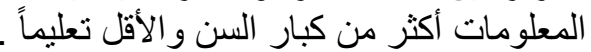

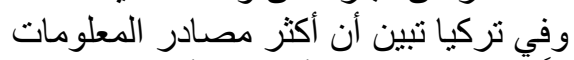

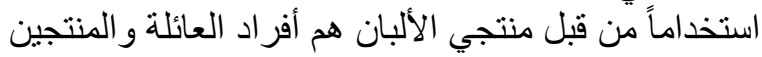

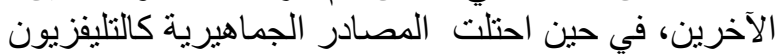




\section{و الاجتماعية و الاقتصادية، فقد نم إجر اء هذه الدر اسة بغية

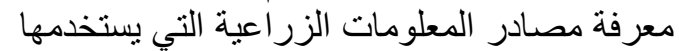

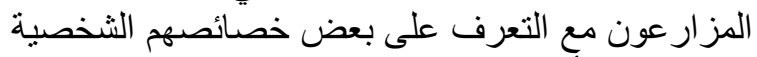

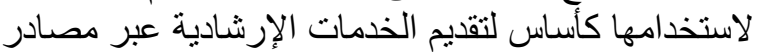

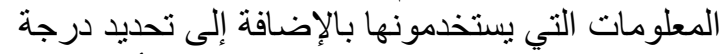

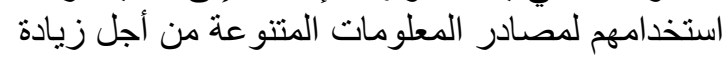

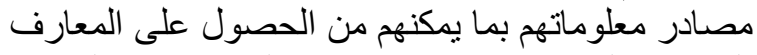 الزر اعية المناسبة لاستخدامها في عمليات الإنتاج الزراعي الزياتي \\ لتحسين دخولهم ومستوياتهم المعيشية.

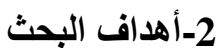

1. التعرف على مصادر المعلومات التي يعتمد عليها

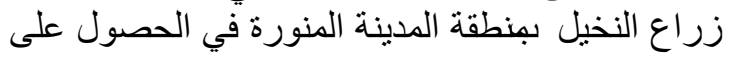
معلوماتهم الزر اعية.

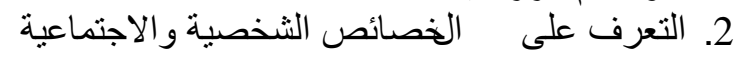
و الاقتصادية للزر اع المبحوثين.

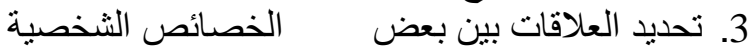

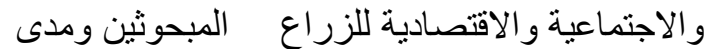
استخدامهم لمصادر المعلومات المختلفئة العادئ.

\section{3- 3- الطريقة البحثية}

\section{-1-3-عينة البحث}

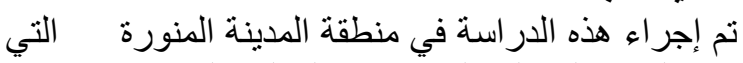
تقع في الجزء الثمالي الغربي من المملكة العربية المباء

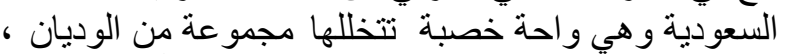
وقد اكتسبت أهميتها من نوفر مياهها أر اضيها ـ ويعد النشاط الزر اعي من الاعن الأنشطة الاقتصادية الأساسية بالمنطقة، خاصة زريطة راعة النخيل وقد تمور المدينة المنورة شهرة عالمية خاصةً (العجوة).

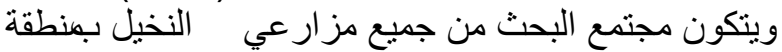

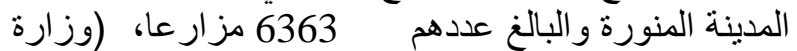

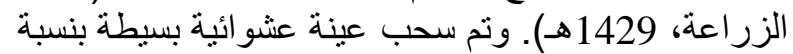

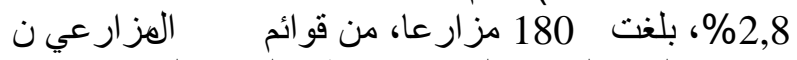

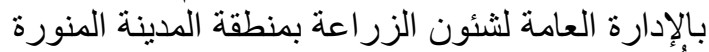

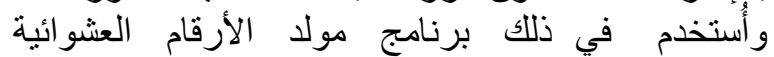
(Random number generator) . 2-3-جمع البيانات وتحليلها

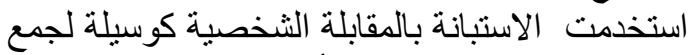

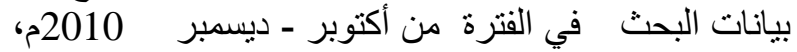

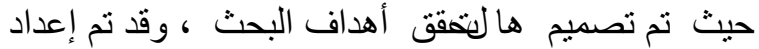

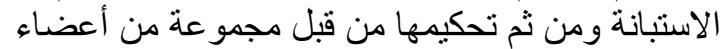

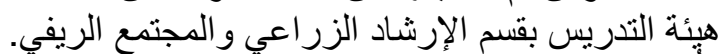

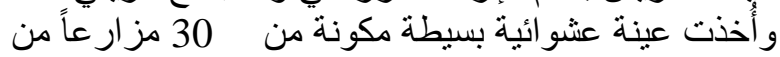

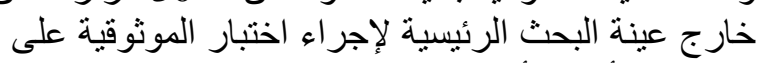

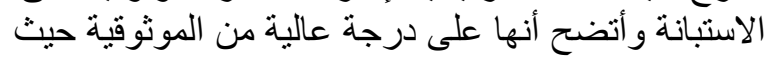

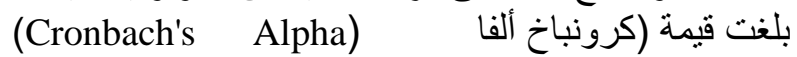
= 0,811)، ولتحليل بيانات هذه الدراسة استخدمت كل من (C)
مصادر المعلومات التي يعتمد عليها السكان في استقاء

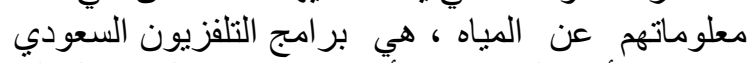

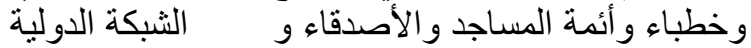

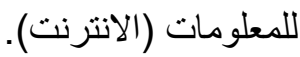

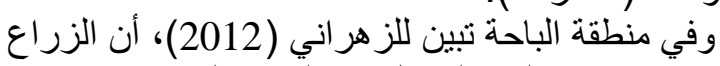

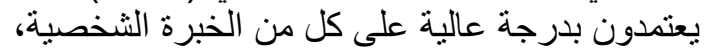

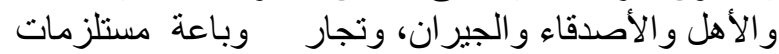

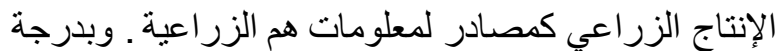

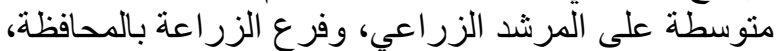

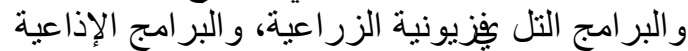

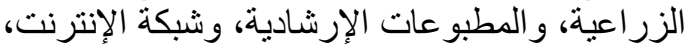

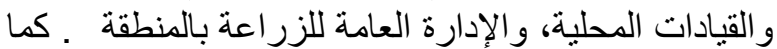

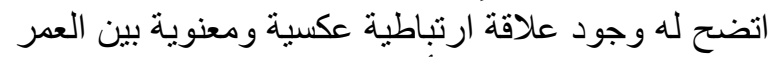

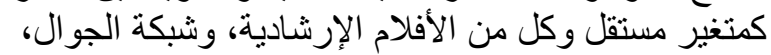

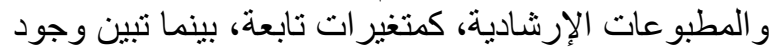

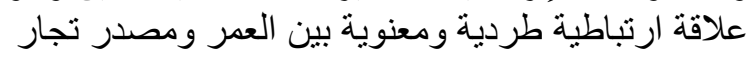

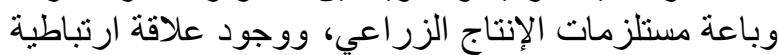

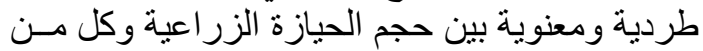

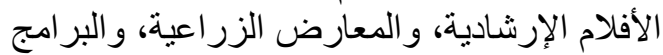

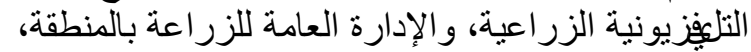

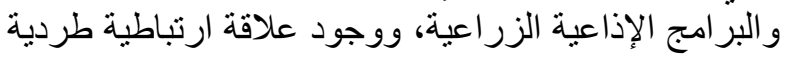

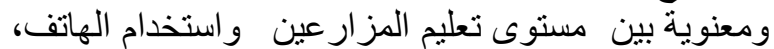

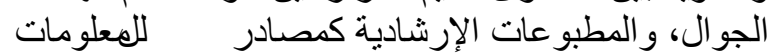

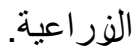

ويتنوع مستوى اعتماد الزراع على الهصادر المختلفة والفئة

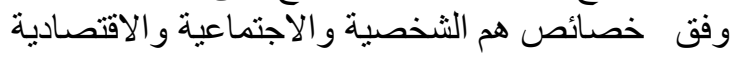

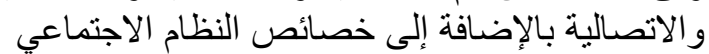

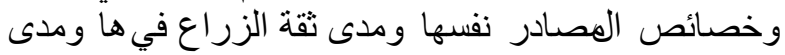

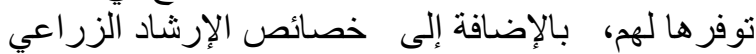

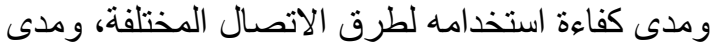

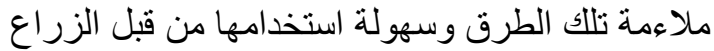

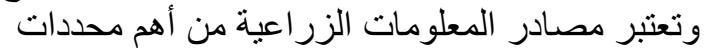
استخدام الزراع للتقنيات الزر اعية الحديثة

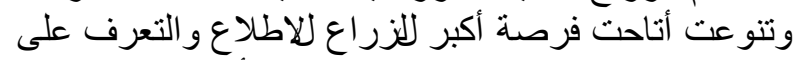

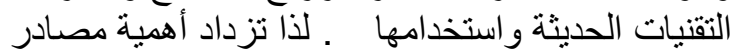

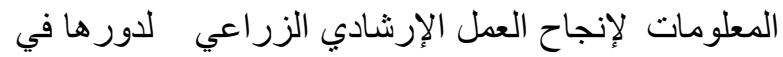

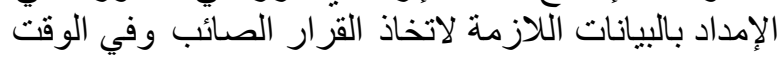

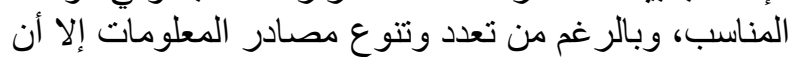

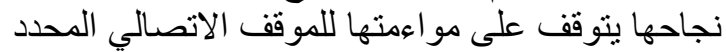
و الخصائص الثخصية و الاقتصادية و الاجتماعية للمستفيدين الاتصالين منها.

ونظر أ لأن تخطيط العمل الإرشادي السليم يتطلب

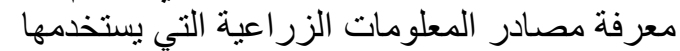

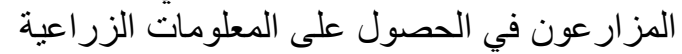

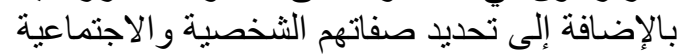

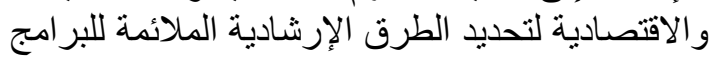

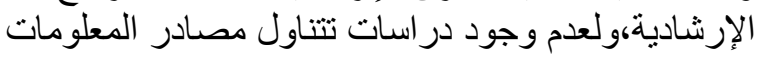
الزراعية التي يستخدمها مز ارعو النية النخيل بمنطقة المدينة

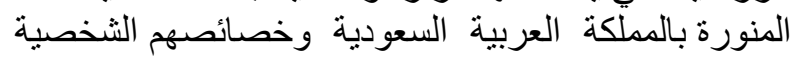


الزر اعة و البيئة بالمقاطعة تعد من المصادر الهامة

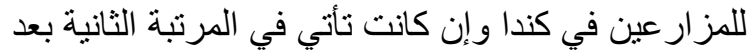

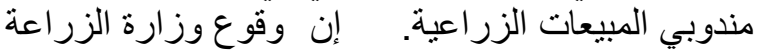

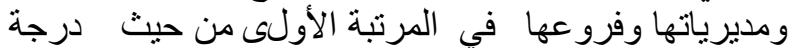

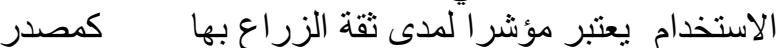

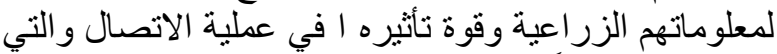

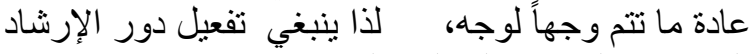

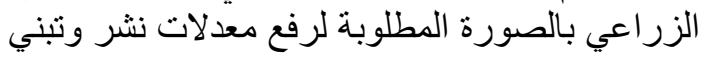

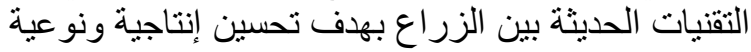

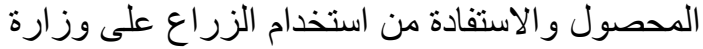

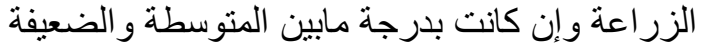

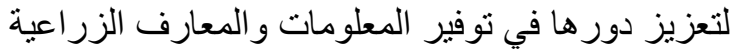

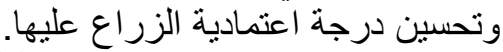

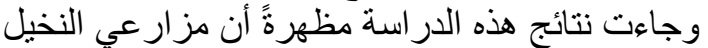

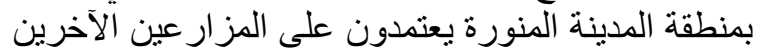

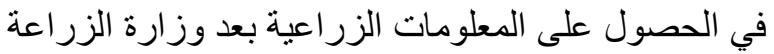

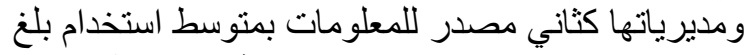

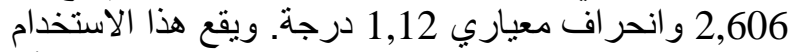

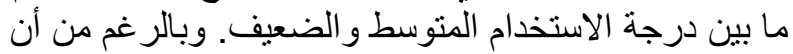

وقوع المزارعين الآخرين في المرتبة الثانية في درجة الثية

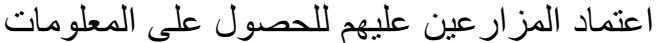

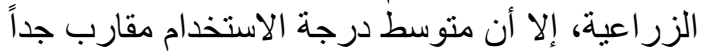

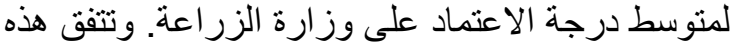
، 2006

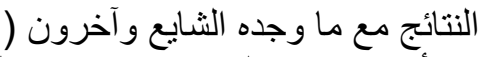

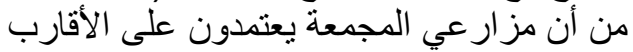

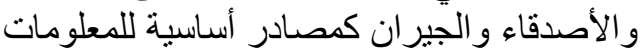

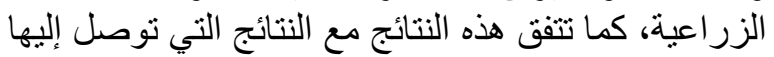

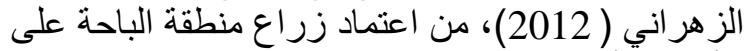

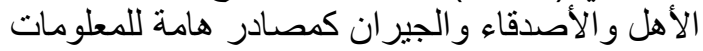

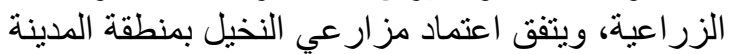
المنورة مع المز ارعين الآخرين مع ما وجده الضريس النيس
النسب المئوية، و المتوسط الحسابي، و الانحر اف المعياري،

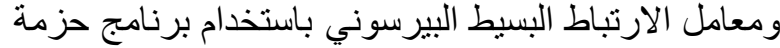
التحليل الإحصائي للعلوم الاجتماعية SPSS.

\section{4-نتائج البحث ومناقشتها}

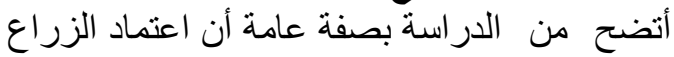

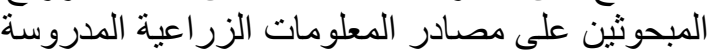

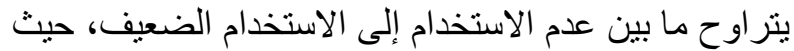
بلغ المتوسط الحسابي العام ل لدرجة الاستخدام

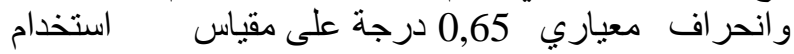
الرباعي (1 = لا استخدم ، 2 = استخدام ضعيف، استخدام متوسط، 4 = استخدام عالي). وتبين من بيانات

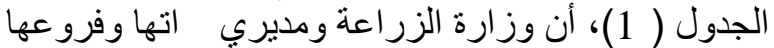

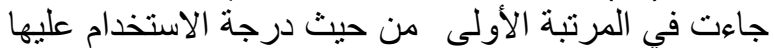

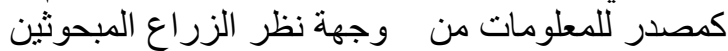
بمتو سط حسابي 2,628 و انحر اف معياري

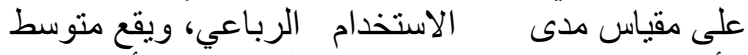

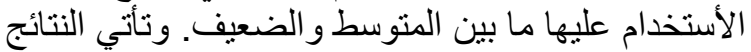

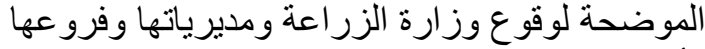

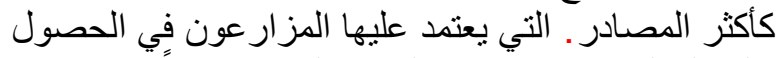

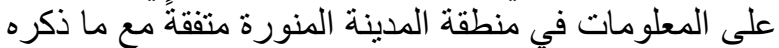

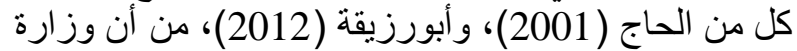

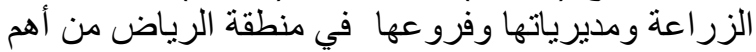

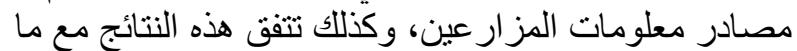

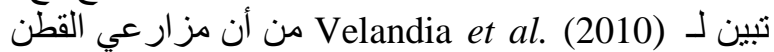

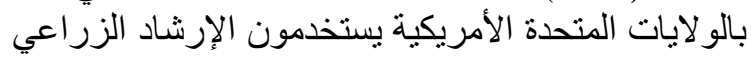

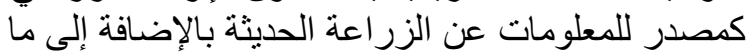

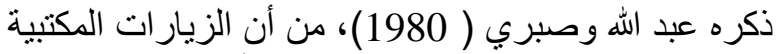

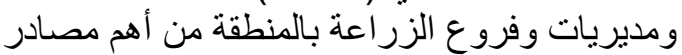

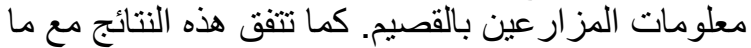
أورده ( ) Shaw, 1993 (Sh)، من أن إدارة

جدول (1): نسب ومتوسطات مصادر المطلومات التي يعتمد عليها زراع النخيل المبحوثين بنطقة المدينة المنورة مرتبة

حسب المتوسط الحسابي (ن = 180).

\begin{tabular}{|c|c|c|c|c|c|c|}
\hline الالحعراف & الحستوسط & لا استخدام & ضع ض & متوسط & عالي & مستوى الاستخدام \\
\hline 1,29 & 2,628 & 33,9 & 7,2 & 21,1 & 37,8 & وز ارة الزر اعة ومديريلتها وفرو عها \\
\hline 1,12 & 2,606 & 25,0 & 15,0 & 34,4 & 25,6 & مزارعون آخرون \\
\hline 1,02 & 2,000 & 42,8 & 23,9 & 23,9 & 9,4 & نشر ات إرشادية \\
\hline 0,98 & 1,950 & 43,9 & 23,3 & 26,7 & 6,1 & البرامج الزر اعية التلبفزيونية \\
\hline 0,89 & 1,783 & 50,0 & 24,4 & 22,8 & 2,8 & البرامج الزر اعية الإذاعية \\
\hline 1,08 & 1,728 & 62,8 & 14,4 & 10,0 & 12,8 & الكتب و المر اجع العلمية \\
\hline 0,96 & 1,700 & 58,9 & 18,9 & 15,6 & 6,7 & مصانع التمور \\
\hline 0,91 & 1,633 & 62,2 & 16,7 & 16,7 & 4,4 & الجمعيات التعاونية الزر اعية \\
\hline 0,85 & 1,600 & 60,0 & 23,9 & 12,2 & 3,9 & شركات ومؤسسات بيع مدخلات الإنتاج الزر اعي \\
\hline 0,92 & 1,578 & 66,1 & 15,6 & 12,8 & 5,6 & كليات الزر اعة ومر اكز ها الإرشادية \\
\hline 0,91 & 1,561 & 67,8 & 13,3 & 13,9 & 5,0 & مراكز الأبحاث الزراعية \\
\hline 0,85 & 1,539 & 66,7 & 15,6 & 15,0 & 2,8 & المعارض الزر اعية \\
\hline 0,84 & 1,489 & 69,4 & 16,7 & 9,4 & 4,4 & النظم الخبيرة (بر امج الحاسب الآلي الزراعية) \\
\hline 0,81 & 1,456 & 71,1 & 15,6 & 10,0 & 3,3 & المو اقع الزر اعية على الانترنت \\
\hline
\end{tabular}


معياري 1.08 درجة ويستخدم بعض المز ارعين الكتب

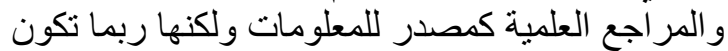
مناسبة أكثر للفئات المتعلمة منهم أما الفئات غير المنات المتعلمة

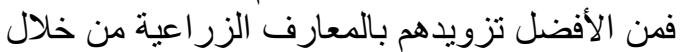

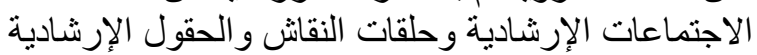

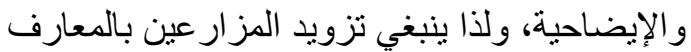

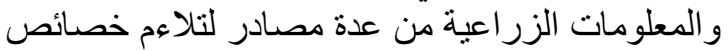

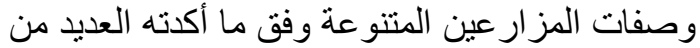

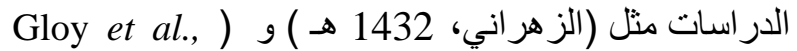

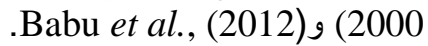
وجاءت كليات الزر اعة ومر اكز ها الإرشادية ومر اكز الزئ الأبحاث الزر اعية و المعارض الزراعة الزراعية في مر اكز متأخرة

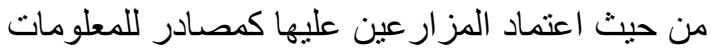

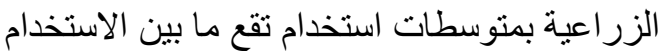

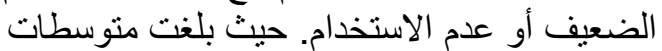
الاستخدام لها معياري 0,92، 0,91، 0,85 على الأن التوالي.

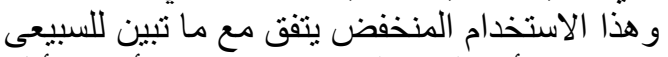
(2006)، من أن كليات الزراعة ومر الكز الكز الأبحاث أقل

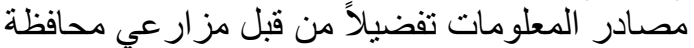

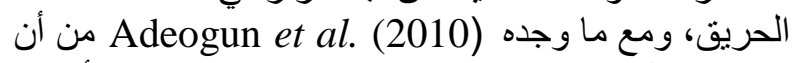
مزارعي الكاكاو في نيجيريا يستخدمون مر اكز الأبحاث

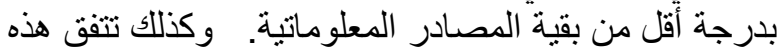

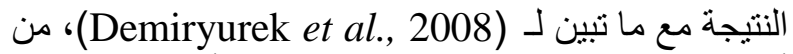
أن المؤسسات البحثية وباحثي الجامعات هم أقل

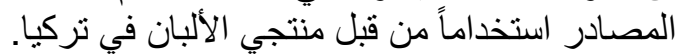

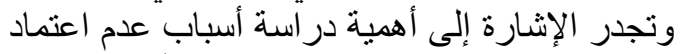

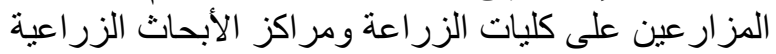

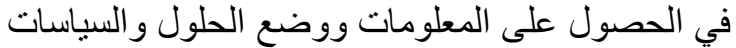

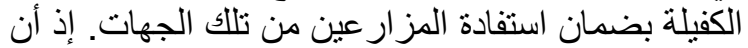

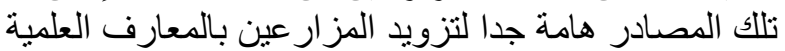

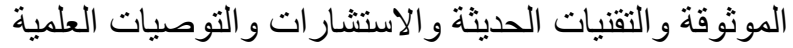

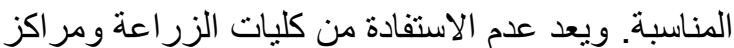

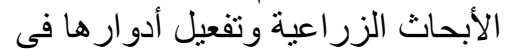
إرشاد المزار الزراعين خلل وقصيل أدور و واضح في النظام المعرفي الزراعي في المملكة يقلل من فعالية وكفاءة القئ القطاع المعاع

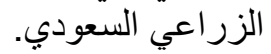

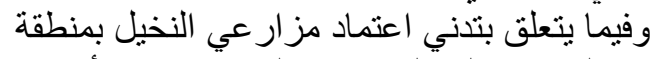

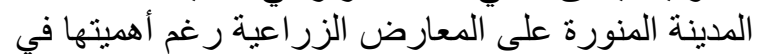

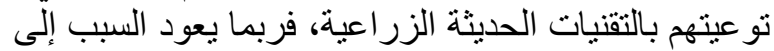

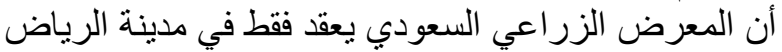

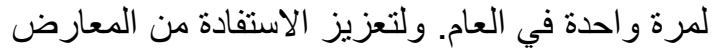

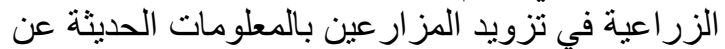

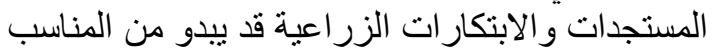

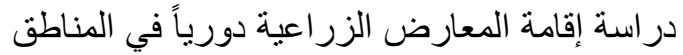

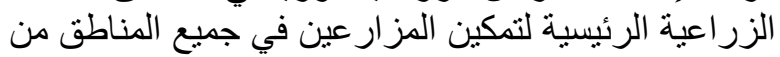
الاطلاع على المستجدات الزر اعية الزئ. ومن الملفت للنظر أن مز ارعي النخيل بمنطقة النية المدينة

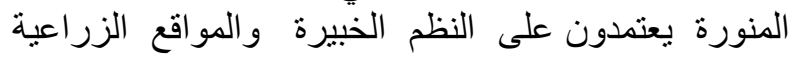

(2009)، من اعتماد المز ارعين في الجمهورية اليمنية على لإئ

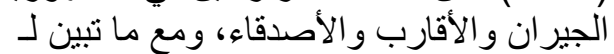

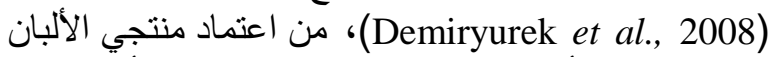

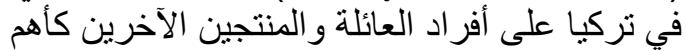

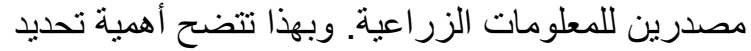

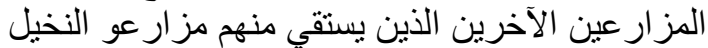

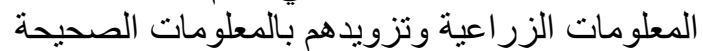

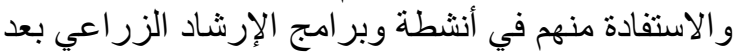

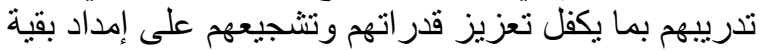

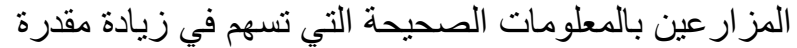
المز ارعين على الإنتاج الزراعي الاعي بكفاءة عالية.

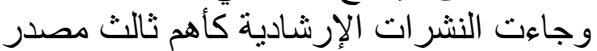

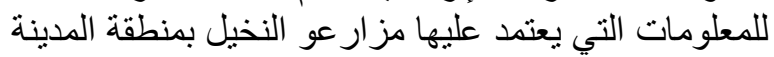

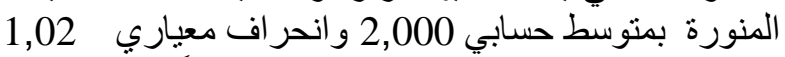
درجة وهذا المستوى من الاستخدام يعد ضعيفاً على مقياس الري

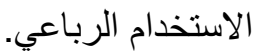

ويأتي اعتماد مزارعي الريار النخيل في منطقة المدينة المنورة

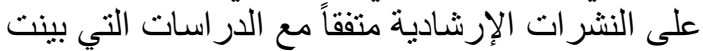

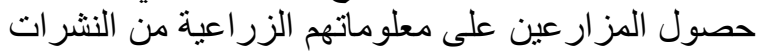

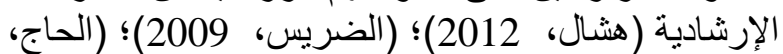

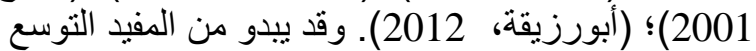

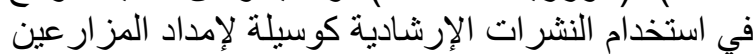

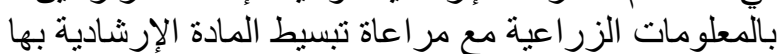

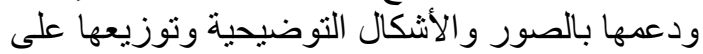

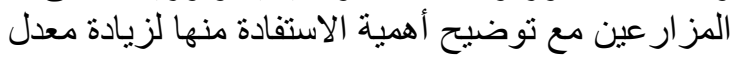

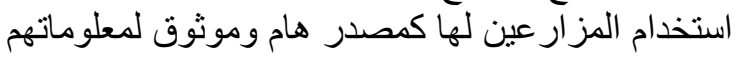

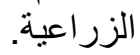

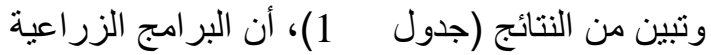

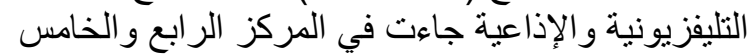

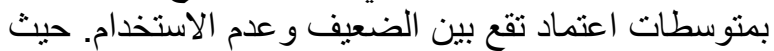

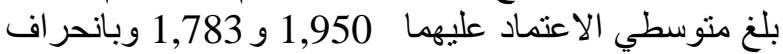

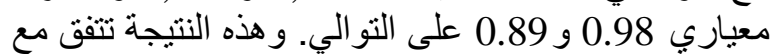

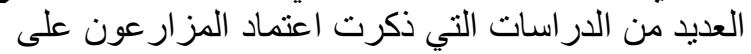

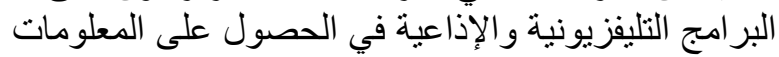

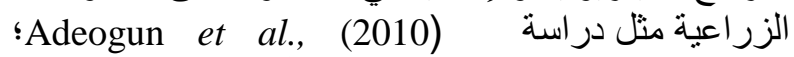

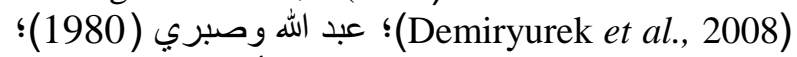
(الضريس، 2009)؛ (الحاج، 2001)؛ (أبورزيقة، 20012)؛ (2001)؛ (Fawole, (2008) ؛para, (2008) و الثايع و آخرون (2006)

(2006). و إلا أن مستويات اعتماد المز ارعين في منطقة

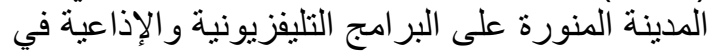

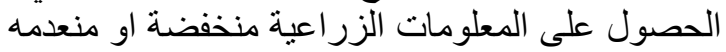

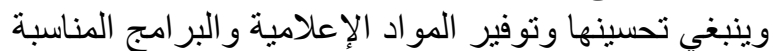

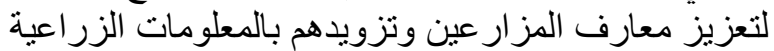

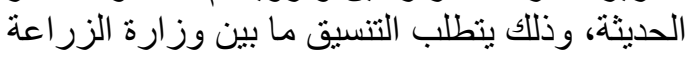

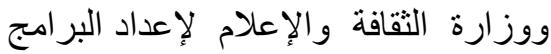

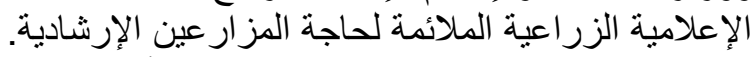

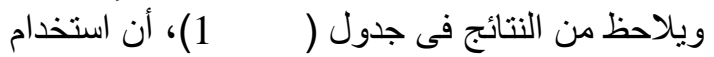

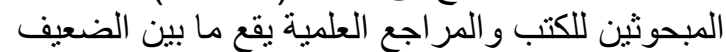

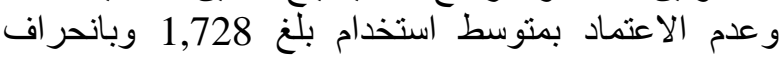


افر اد أسر هم في الزراعة، وأن 23,3\% يعمل 23:3 فرد و احد، و22,8\% يعمل فردان أو أكثر في الزر اعة اعن.

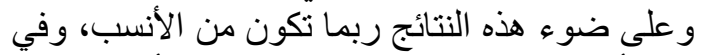
ظل كبر أعمار المزارعين وقاه النّة العاملين من أسر هم في الأسي وفي

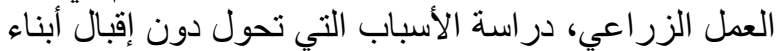

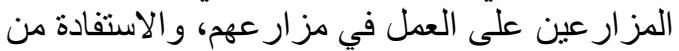

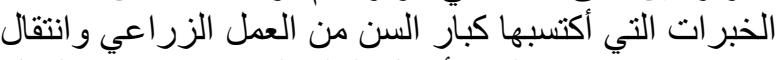
خبر اتهم ومعارفهم إلى الأجيال التالية لضمان الضمان استدامة العمل التحل

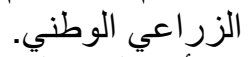
أما بالنسبة لمساحة المزرعة فيلاحظ أن غالبية الزراع التراع

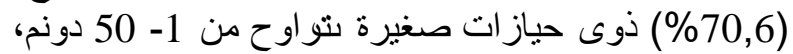

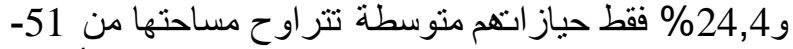
100 دونم، و 50 \% فقط حياز اتهم كبيرة تبلغ مساحتها أكثر من 100 دونم، في حين بلغ منوسط المساحة 49,18 دونما و لبنحر اف معياري ذللك في ضعف أن لم يكن عدم استخدامهم لمصادر المعلومات المختلفة.

2-4-العلاقة الارتباطية بين بعض الصفات الثاتية الثخصية والاجتماعية والاقتصادية للزراع العاع ومصادر معلوماتهم الزراعية

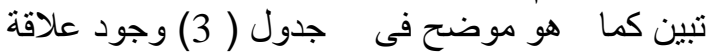

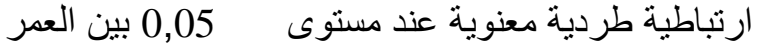
كمتغير مستقل كل من وز ارة الزية الزر اعة ومندية ومديرياتها

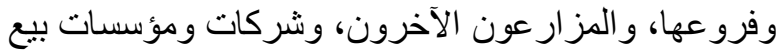

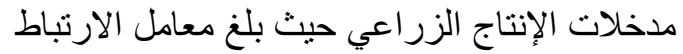

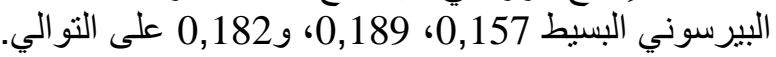

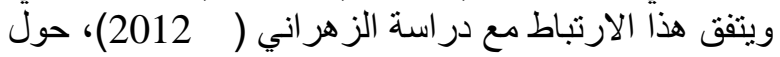

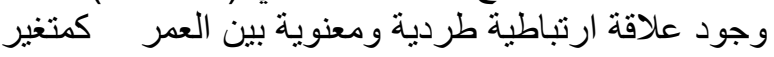

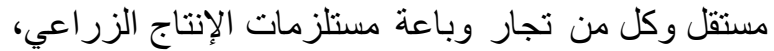

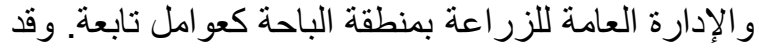

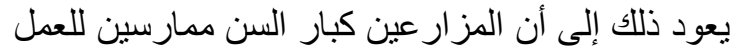
الزر اعي لفترة طويلة ولديهم علاقات ألين أوسع و إدر الك أكبر الكير

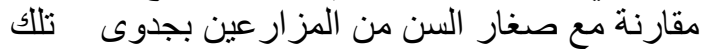

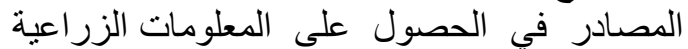
للاستفادة منها في الإنتاج الزراعي.

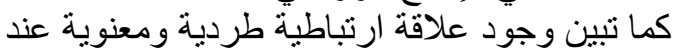

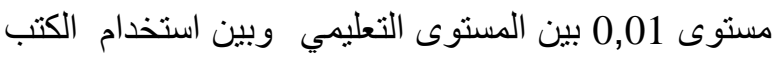

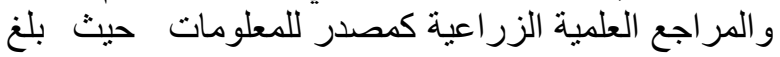

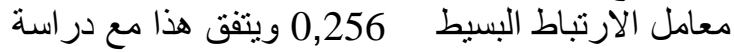
الزهر اني ( 2012)، حول وجود وليط علاقة ارتباطية طردية

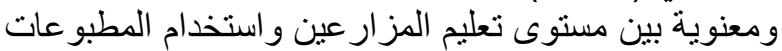

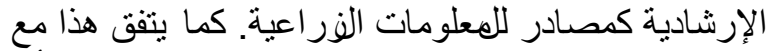

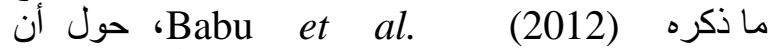

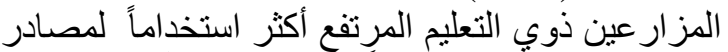

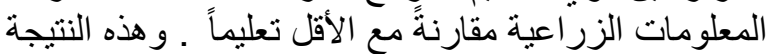

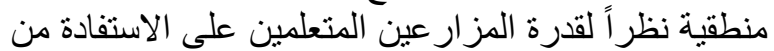

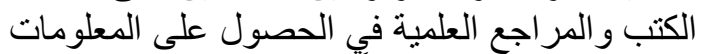
و المعرفة الزر اعية مقارنة مع قليلي التعليم من المزار العين.

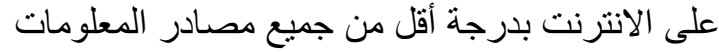
المدروسة. حيث جاء متوسطي الاستخدام لهما ما بين الإنين

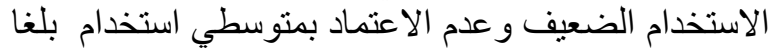
1,489، 1,456 وبانحر اف معياري

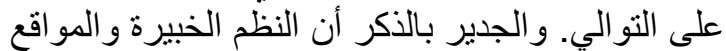

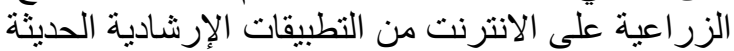

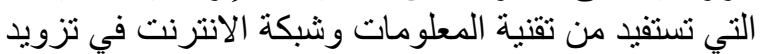

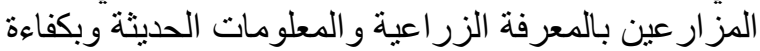

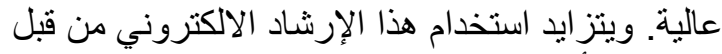

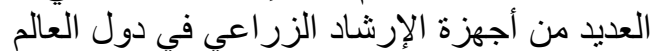

Hemmati and Sefidian, 2006, Kramer-Leblanc ) and Greg, 2010, Mukhebi et al., 2007, Meera et al., 2004, Amir and Mehdi, 2010, Samantha et al., 2011, Lippert, and Plank, 1999, Abbas et al. 2003, .(Taragola and Dirk, 2010, and FAO, 2005 ونظر اً لأهمية استخدام الإرشاد الالكتروني بالمملكة

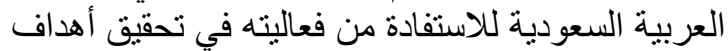

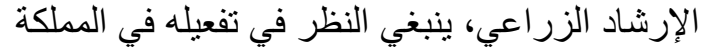

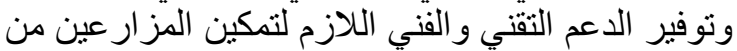

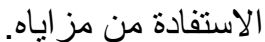

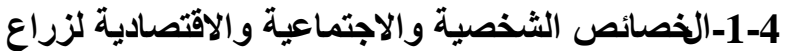
النخيل بمنطقة المدينة المنورة الاجنية

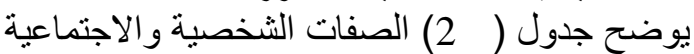

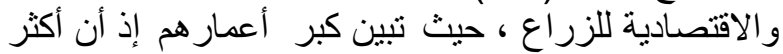

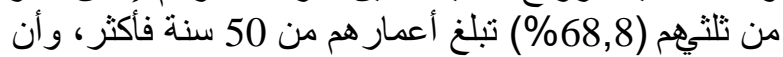

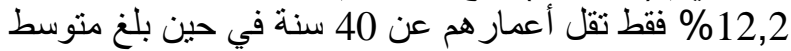

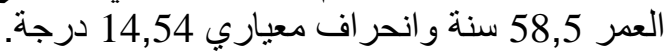

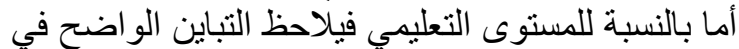

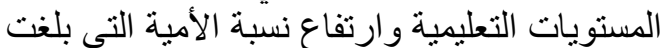

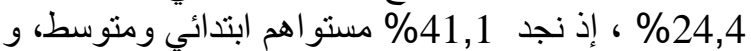

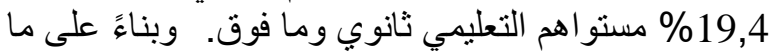

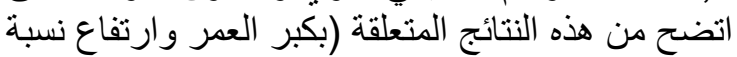

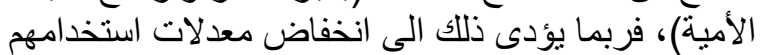

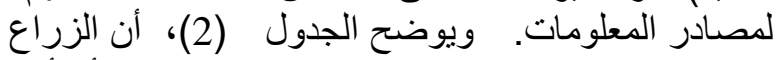

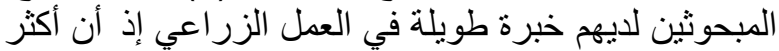
من تلثيهم)

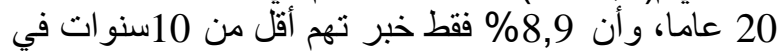
حين بلغ منوسط عدد سنوات الخبرة

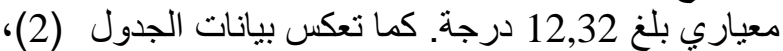

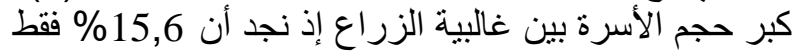

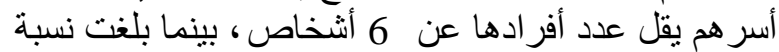

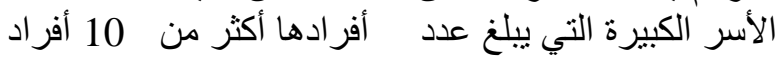
فأكثر 38,9 \%

وبالر غم من كبر حجم الأسرة والذب بلغ متوسط عدد

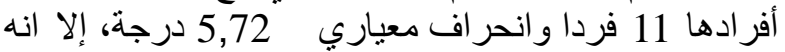

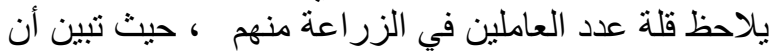
أكثر من نصف الزراع (53,9\%) لا يعمل أي فرد من 
جدول(2): الصفات الثخصية والاجتماعية والاقتصادية للزراع المبحوثين بمنطقة المدينة المنورة (ن =180).

\begin{tabular}{|c|c|c|c|}
\hline \multicolumn{2}{|c|}{ الصفة } & \multicolumn{2}{|c|}{ الصفة } \\
\hline$\%$ & عدد أفر & $\%$ & 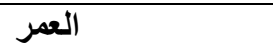 \\
\hline \multirow{2}{*}{15,6} & \multirow{2}{*}{1 - 5 - 5 أفراد } & 5,0 & أقل من 30 سنة \\
\hline & & 7,2 & 30- أقل من 40 سنة \\
\hline 45,5 & 10-6 أفر اد & 18,9 & 40- أقل من 50 سنة \\
\hline 38,9 & 11 فرد فأكثر & 24,4 & 50- أقل من 60 سنة \\
\hline \multicolumn{2}{|c|}{ عدد أفر اد الأسرة العاملين بالزراعة } & 28,3 & 60- أقل من 70 سنة \\
\hline \multirow{2}{*}{53,9} & \multirow{2}{*}{ ل ل الا يوجد } & 16,1 & 70سنة فأكثر \\
\hline & & \multicolumn{2}{|c|}{ الحالة التعليمية } \\
\hline 23,3 & فرد و احد & 24,4 & امي \\
\hline 16,7 & فردان & 15,0 & يقر أ ويكتب \\
\hline \multirow{2}{*}{6,1} & \multirow{2}{*}{3 أفر اد فأكثر } & 18,9 & ابتدائي \\
\hline & & 22,2 & متوسط \\
\hline \multicolumn{2}{|c|}{ مساحة المزر عة الكلية (دونم) } & 10,0 & 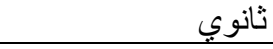 \\
\hline 12,8 & $10-1$ & 8,3 & جامعي \\
\hline 27,2 & $25-11$ & 1,1 & فوق جامعي \\
\hline \multirow{2}{*}{30,6} & \multirow{2}{*}{$50-26$} & \multicolumn{2}{|c|}{ عدد سنوات الخبرة بالزر اعة } \\
\hline & & 1,7 & 1 - 5 سنوات \\
\hline 12,2 & $75-51$ & 7,2 & 6- 10 سنوات \\
\hline \multirow{2}{*}{12,2} & \multirow{2}{*}{$100-76$} & 9,4 & (11- 15 سنة \\
\hline & & 12,8 & 16- 20 سنة \\
\hline \multirow{2}{*}{5,0} & \multirow{2}{*}{ أكثر من 100} & 11,1 & 21- 25 سنة \\
\hline & & 57,8 & 26 سنة فأكثر \\
\hline
\end{tabular}

جدول ( 3): العلاقة الارتباطية بين بعض الصفات الثخصية والاجتماعية والاقتصادية للزراع ومصادر معلوماتهم الزراعية.

\begin{tabular}{|c|c|c|}
\hline معامل الارتباط & استخدام مصـادر المعلومات & المتغيرات المستقلة \\
\hline $0,157^{*}$ & وز ارة الزر اعة ومديرياتها وفروعها & \multirow{3}{*}{ 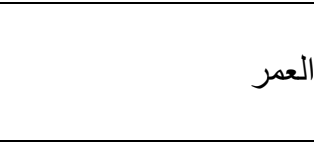 } \\
\hline $0,189^{*}$ & مز ارعون آخرون & \\
\hline $0.182^{*}$ & شركات ومؤسسات بيع مدخلات الإنتاج الزر اعي & \\
\hline $0.256^{* *}$ & الكتب و المر اجع العلمية الزر اعية & 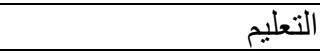 \\
\hline $0,191^{*}$ & مزارعون آخرون & مساحة المزرعة \\
\hline $0,159^{*}$ & وز ارة الز ارعة ومديرياتها وفروعها & \multirow{8}{*}{ في الزرد أفراد الأسرة العاملين } \\
\hline $0,190^{*}$ & نشر ات إرشادية & \\
\hline $0.147^{*}$ & الكتب و المر اجع العلمية الزر اعية & \\
\hline $0,166^{*}$ & المو اقع الزر اعية على الانترنت & \\
\hline $0,156^{*}$ & البرامج الزر اعية التلفزيونية & \\
\hline $0,189^{*}$ & البر امج الزر اعية الإذاعية & \\
\hline $0,260^{* *}$ & المعارض الزر اعية & \\
\hline $0,183^{*}$ & النظم الخبيرة & \\
\hline
\end{tabular}

لتخصصهم في العمل الزر اعي مقارنة مع ذوي المساحات

الصغيرة.

و عكس الجدول (3) وجود علاقة ارتباطية طردية

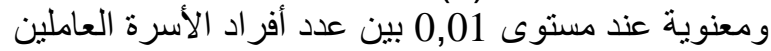
في الزراعة وبكل المعارض الزر اعية و وعند مستوى 0,05

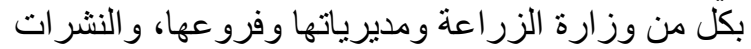
الإرشادية، و الكتب و المر اجع العلمية الزر اعية،
وأوضح (جدول 3)، وجود علاقة ارتباطية طردية

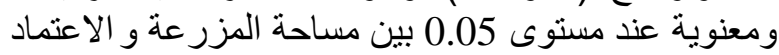

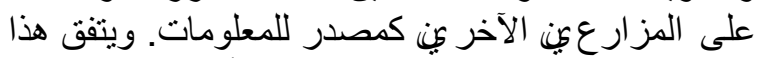

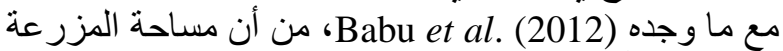

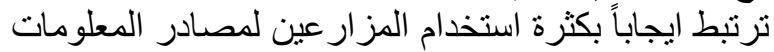

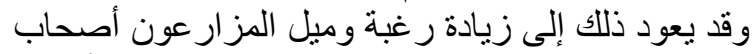

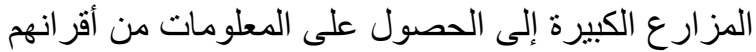


وتحسين مهار ات الاتصال لاى المهندسين الإين

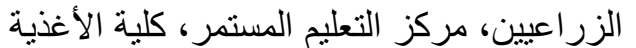

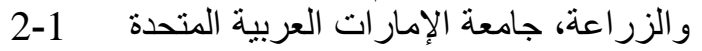

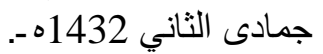

آل عباس، حسين أحمد سعود ( 2012). مستوى وعي

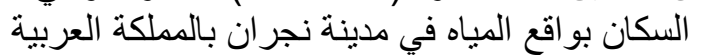

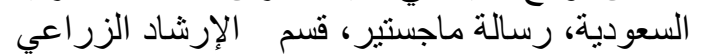
و المجتمع الريفي، كلية علوم الأغذية و الزئية الزراعة، جامعة المللك سعود. السبيعي، فيصل سلطان ( 2006). الطرق الإرشادية

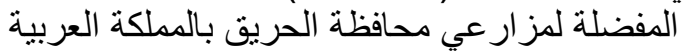
السعودية. مجلة الجمعية السعودية للعلوم الزر اعية. العدد الأول. المجلد السادس.

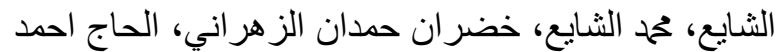

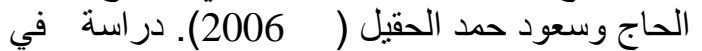

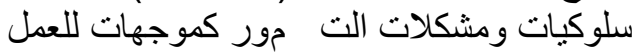

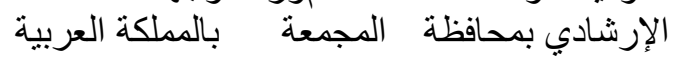
السعودية، مجلة الإسكندرية للتبادل العلمي، 27

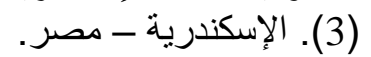

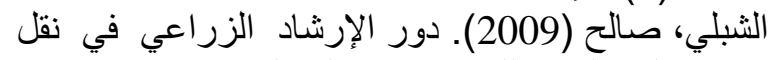
التكنولوجيا للمز ارعين. على الر ابط الزئ http://www.khairbaladna.com

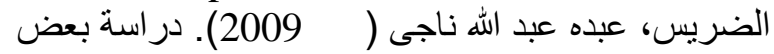

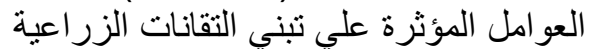

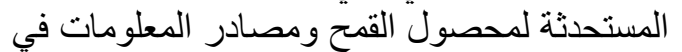

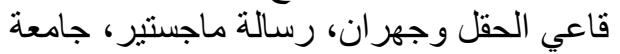
صنعاء كلبة الزراعة ــ الجمهورية اليمنية.

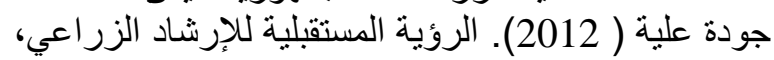
المجلة الزر اعية. على الر ابط الرئل http://www.digital.ahrm.org.eg رادكون ( 2013). شبكة معلومات التنمية الزر اعية

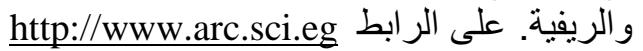

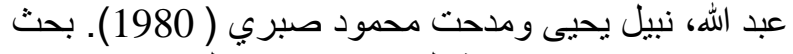

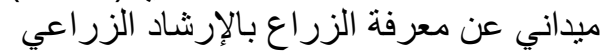
ومصدادر المعلومات بمنطقة القصيم بالمملكة العربية

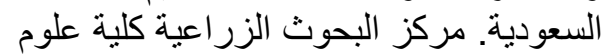
الأغذية و الزر اعة، جامعة الهلك سعود.

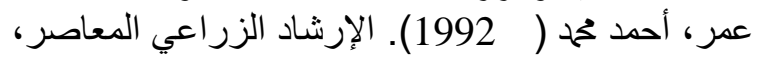

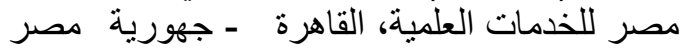

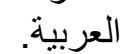

هشال، زياد عبداله حمح (2012). دراسة تحليلية لو اقع العمل

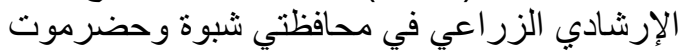

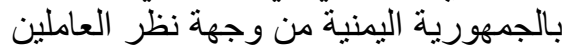
الإرشاديين، رسالة ماجستير ، قسم الإرشاد الزئة الزراعي

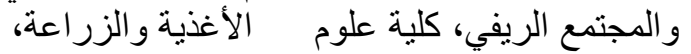
جامعة الملك سعود.

وزارة الزر اعة، الإدارة العامة لشئون الزر اعة بمنطقة المدينة المنورة (1429 هـ). التقرارة العامة الزير السنوي.
و المو اقع الزر اعية على الانترنت و البر امج الزر اعية

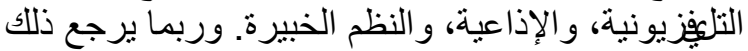

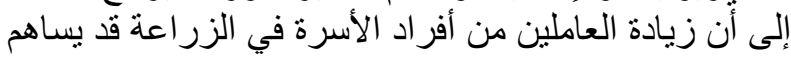

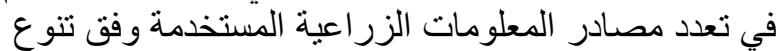

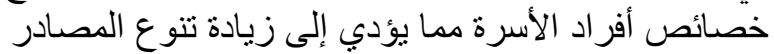

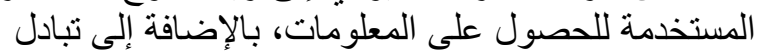

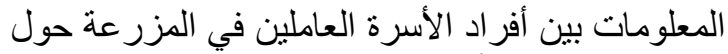

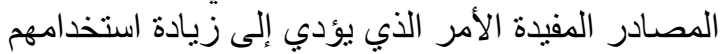
كأفر اد لمصادر المعلومات المتنوعة الأئ.

التوصيات وبناءاً على نتائج هذه الدر اسة يمكن التوصية بالتالي:

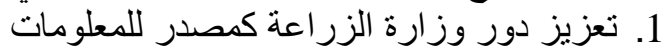

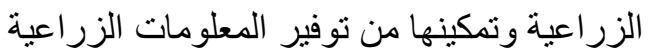
لللمز ارعين وفق احتياجاتهم الفعلية.

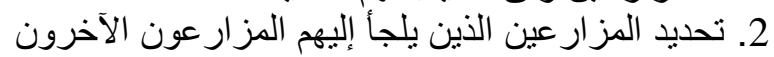

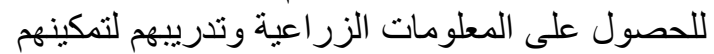

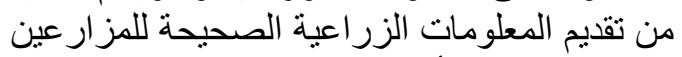

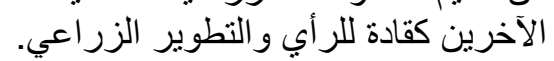

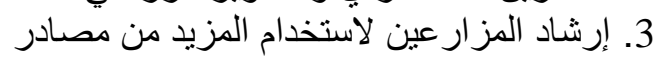

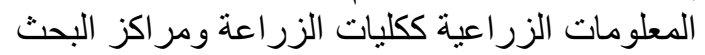

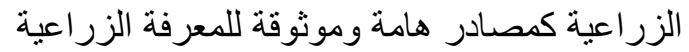
والتقنيات الحديثة، وتعزيز الدور الإرشادي لتلكي

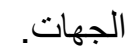

4. مر اعاة توفير المعلومات الزر اعية بطرق حديثة ومتعددة

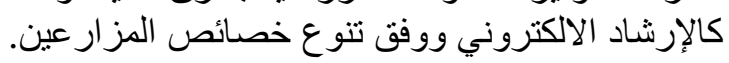

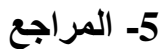

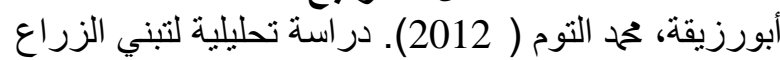

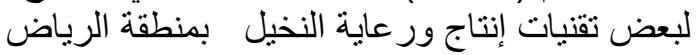

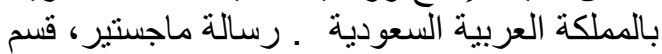

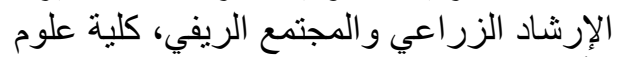

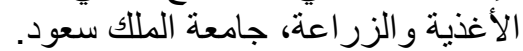

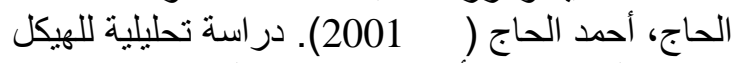

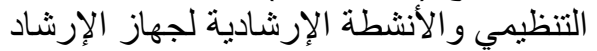

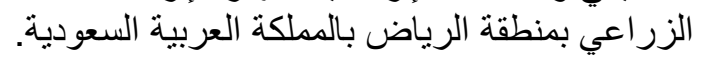

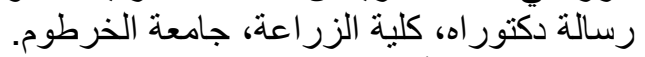

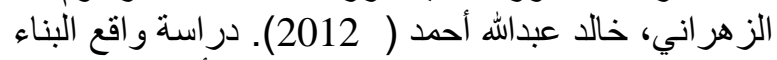
التنظيمي لجهاز الإرشاد الزر اعي و أنشطته بمنطقة

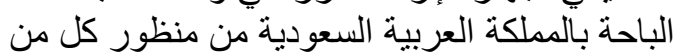

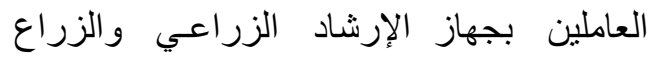

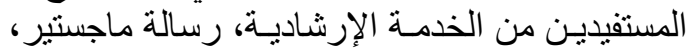

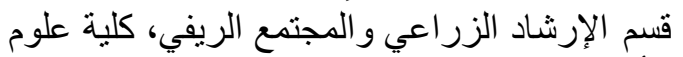

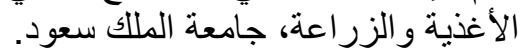

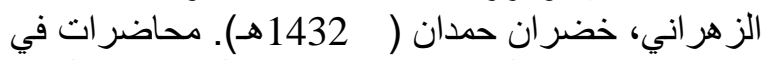
تخطيط البرامج الإرشادية الزراعية لنية لتطوير 
Abbas M., Sheikh A.D., Sher M. and Ashfaq M. (2003). Role of electronic media in the adoption of agricultural technologies by farmers in the Central Punjab-Pakistan. Int. J. Agric. Biol., 5(1): 22-25.

Adeogun S.O., Olawoye J.E. and Akinbile L.A. (2010). Information sources to cocoa farmers on cocoa rehabilitation techniques (CRTs) in selected states of Nigeria. Journal Media and Communication Studies, 2 (1):9-15.Retrieved January 23, 2013, from http://www.academicjournals.org.

Amir A. and Mehdi M. (2010). Determining challenges in the application of E-Learning in agricultural extension services in Iran. American-Eurasian J. Agric. \& Environ. Sci., 9 (3): 292-296.

Babu S.C., Claire J., Kwadwo, A.O. and Senthil K.G. (2012). Farmers Information Needs and Search Behaviors: Case Study in Tamil Nadu, India. International Food Policy Research Institute, sustainable solutions for ending hunger and poverty. Retrieved January 28, 2013, from http://www.ifpri.org.

Demiryurek K., Edren H., Ceyhan V., Astasever S. and Uysal O. (2008). Agricultural information systems and communication networks: the case of dairy farmers in the Samsun province of Turkey. Information Research Vol. 13 No. 2. Retrieved January 22, 2013, from http://informationr.net/ir/132/paper343.html.

FAO (2005). Modernizing national agricultural extension systems. A practical guide for the policy makers of developing countries by Qamar, senior officer (Agricultural Training \& Extension) Research, Extension and training Division, sustainable Development Department Food and Agriculture Organization of the United Nations, Rome,169.

Fawole O.P. (2008). Pineapple farmers information sources and usage in Nigeria. Bulgarian Journal of Agricultural Sciences, 14 (4): 381- 389. Retrieved January 23, 2013, from http://www.agrojournal.org/14/0405-08.pdf.

Gloy B.A., Jay T.A. and Linda D.W. (2000). Sources of information for commercial farms: usefulness of media and personal sources. International Food and Agribusiness Management Review 3: 245- 260. Retrieved January 21, 2013. from http://agfinance.dyson.cornell.edu.

Hall L., Dunkelberger J., Ferreira W., Prevatt J. W. and Martin N. R. (2003). Diffusionadoption of personal computers and the internet in farm business decisions: Southeastern beef and peanut farmers." Journal of Extension [On-line], 41(3) Article 3FEA6. Available at: http://www.joe.org/joe/2003june/a6.

Hemmati A. and Sefidian E. (2006). E-learning and investigation on its application in onthe job training for the staff of AREO, Proceedings of the Iranian agricultural education seminar, Tarbiat Modares University, Iran, 1-2 Nov, pp: 221-232.

King D. (1993). Facing the image deficit. Journal of Extension. [online] http://www.joe.org.

Kramer-Leblanc C. and Greg C. (2010). Capacity Building of Farmers through an e-Extension Model: Challenges and Opportunities. Multi stakeholder Dialogue on Implementing Sustainable Development. USDA.

Lippert R.M. and Plank C.O. (1999). Response to a first time use of internet in service training by agricultural extension agents. The Journal of Natural Resource and Life Science Education, 28: 53-56.

Meera, Shaik N., Jhamtani A. and Rao D.U.M. (2004). Information and communication technology in agricultural development: a comparative analysis of three projects from India. AgREN Network Paper No.135, ODI. 20p.

Mukhebi A.W., Kundu J., Okolla A., Wambua M., Ochieng W. and Fwamba G. (2007). Linking farmers to markets through modern information and communication technologies in Kenya. Proceedings of the $2^{\text {nd }}$ International AAAE Conference, Accra, Ghana.

Opara U. N. (2008). Agricultural Information Sources Used by Farmers in Imo State, Nigeria. Information Development, Retrieved January 23, 2013. From http://idv.sagepub.com/content/24/4/289. full.pdf.

Samantha R.R., Komar S., Schilling B., Thomas S.R., Carlo J. and Colucci S.J. (2011). Meeting extension programming needs with technology: a case study of agritourism webinars. Journal of 
Extension, 41(6):1-14.

Shaw Kenneth L. (1993). Farmers' use of information sources in British Columbia. Master of Science-Administrative, Adult and Higher Education, University of British Columbia. Retrieved January 28, 2013, from https://circle.ubc.ca.

Taragola N. M. and Drik F.V. (2010). Factors affecting the internet behavior of horticultural growers in Flanders,
Belgium. Computers and Electronics in Agriculture, 70: 369-379.

Velandia M., Dayton M.L., Amanda J., Roland K.R., James A.L., Burton C.E. and Steven W.M. (2010). Precision farming information sources used by cotton farmers and implications for extension. Journal of Extension Vol. 48 No. 5. Retrieved January 25, 2013, from http://www.joe.org. 